\title{
SÍNTESIS CURRICULARES
}

\section{Mauricio Beuchot}

Doctor en Filosofía por la Universidad Iberoamericana. Profesor en el posgrado de la Facultad de Filosofía y Letras de la UNAM e investigador en el Instituto de Investigaciones Filológicas de la misma universidad. Es fundador del Seminario de Hermenéutica de dicho instituto. Ha escrito varios libros y artículos sobre historia de la filosofía y sobre hermenéutica filosófica. Entre sus libros puede señalarse el Tratado de hermenéutica analógica (UNAM, 2015, 5a. ed.).

\section{Adriana Menassé}

Investigadora del Instituto de Filosofía de la Universidad Veracruzana, doctora en Filosofía por la UNAM y maestra en Filosofía por la New School for Social Research de Nueva York. Ha concentrado su atención en temas de ética, particularmente desde la filosofía de la alteridad en la perspectiva abierta por la obra de Emmanuel Levinas. La pregunta por la justicia la ha llevado a explorar la problemática articulación del orden de sentido, así como algunos puentes entre el derecho religioso y algunas formas del derecho consuetudinario indígena. Se ha interesado también por los puntos de intersección entre la filosofía y la literatura. Entre sus publicaciones destacan La ley y la fisura y Ley, otredad y sentido.

Cossette Galindo Ayala

Es licenciada en Lengua y Literaturas Hispánicas por la UNAM, y doctora en Ciencias de las Religiones por la Universidad Complutense de Madrid con la tesis doctoral titulada Apocalíptica y mística, una 
relación de interdependencia. El enfoque que ha dado a su trabajo como investigadora es el de la Hermenéutica filosófica, cultural y simbólica en la aproximación a los textos bíblicos y apócrifos del Antiguo Testamento. Actualmente participa como docente en la Maestría de Estudios Judaicos de la Universidad Hebraica de México y realiza una estancia postdoctoral en el Instituto de Investigaciones Filológicas de la UNAM.

\section{Martha Fernández}

Doctora en Historia del Arte por la Universidad Nacional Autónoma de México, profesora en la Facultad de Filosofía y Letras y la División de Estudios de Posgrado e investigadora de tiempo completo en el Instituto de Investigaciones Estéticas. Entre sus publicaciones más recientes pueden citarse Estudios sobre el simbolismo en la arquitectura novohispana, La imagen del templo de Jerusalén en la Nueva España y Cristóbal de Medina Vargas y la arquitectura salomónica en la Nueva España. Siglo XVII.

\section{Mónica Magaña Jattar}

Arqueóloga y filósofa de la ciencia. Es licenciada en Arqueología por la Facultad de Antropología de la Universidad Veracruzana (UV), donde desarrolló sus investigaciones en técnicas antiguas y arqueología experimental. Es maestra en Filosofía de la Ciencia y actualmente cursa el doctorado en el Instituto de Investigaciones Filosóficas (UNAM). Realiza sus investigaciones sobre ontoepistemología, filosofía de la técnica y pluralismo; la aplicación teórica de estas nociones para comprender la generación de conocimiento en tiempos antiguos, y las consecuencias e impactos de estas áreas de conocimiento en el concepto de una Filosofía de la Ciencia. Su trabajo ha sido publicado en las revistas La Ciencia y el Hombre, revista de divulgación científica y tecnológica de la Universidad Veracruzana, y Cuicuilco, revista de divulgación científica de antropología de la Escuela Nacional de Antropología e Historia (ENAH).

\section{JULIO HORTA}

Filósofo y comunicólogo. Es licenciado en Ciencias de la Comunicación por la Facultad de Ciencias Políticas y Sociales de la UNAM, y cuenta 
además con la licenciatura en Filosofía por la Facultad de Filosofía y Letras de la misma institución. Realizó la maestría y actualmente está cursando el doctorado en Filosofía de la Ciencia en el Instituto de Investigaciones Filosóficas de la UnAM. Colabora en diferentes proyectos de investigación en el área de Sociolingüística y Cultura en el Instituto de Investigaciones Sociales. Es académico en la Facultad de Ciencias Políticas y Sociales, impartiendo los cursos "Introducción al estudio del lenguaje", "Teoría de la Imagen" y "Semiótica". Entre sus publicaciones recientes están los libros Historia y semiótica.Categorías y relaciones filosóficas en la caracterización del espacio histórico y Humanidades y universidad. La UNAM desde la intertextualidad humanística. 